Digital Signals, Processors and Noise 
Macmillan New Electronics Series

Series Editor: Paul A. Lynn

Rodney F. W. Coates, Underwater Acoustic Systems

W. Forsythe and R. M. Goodall, Digital Control

C. G. Guy, Data Communications for Engineers

Paul A. Lynn, Digital Signals, Processors and Noise

Paul A. Lynn, Radar Systems

A. F. Murray and H. M. Reekie, Integrated Circuit Design

F. J. Owens, Signal Processing of Speech

Dennis N. Pim, Television and Teletext

M. J. N. Sibley, Optical Communications

Martin S. Smith, Introduction to Antennas

P. M. Taylor, Robotic Control

G. S. Virk, Digital Computer Control Systems

Allan Waters, Active Filter Design

\section{Series Standing Order}

If you would like to receive further titles in this series as they are published, you can make use of our standing order facility. To place a standing order please contact your bookseller or, in case of difficulty, write to us at the address below with your name and address and the name of the series. Please state with which title you wish to begin your standing order. (If you live outside the United Kingdom we may not have the rights for your area, in which case we will forward your order to the publisher concerned.)

Customer Services Department, Macmillan Distribution Ltd Houndmills, Basingstoke, Hampshire, RG21 2XS, England. 


\title{
Digital Signals, \\ Processors and Noise
}

\author{
Paul A. Lynn \\ $B S c$ (Eng), ACGI, PhD, MIEE
}

Macmillan New Electronics

Introductions to Advanced Topics

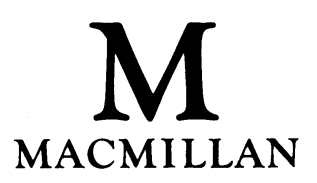


All rights reserved. No reproduction, copy or transmission of this publication may be made without written permission.

No paragraph of this publication may be reproduced, copied or transmitted save with written permission or in accordance with the provisions of the Copyright, Designs and Patents Act 1988 or under the terms of any licence permitting limited copying issued by the Copyright Licensing Agency, 90 Tottenham Court Road, London W1P 9HE.

Any person who does any unauthorised act in relation to this publication may be liable to criminal prosecution and civil claims for damages.

First edition 1992

Published by

THE MACMILLAN PRESS LTD

Houndmills, Basingstoke, Hampshire RG21 2XS

and London

Companies and representatives

throughout the world

Typeset by TecSet Ltd, Wallington, Surrey.

ISBN 978-0-333-54587-4

ISBN 978-1-349-22145-5 (eBook)

DOI 10.1007/978-1-349-22145-5

A catalogue record for this book is available from the British Library 


\section{Contents}

Series Editor's Foreword viii

Preface $\quad$ ix

1 Introduction 1

1.1 Background 1

1.2 Sampling and analog-to-digital conversion 6

1.3 Time-domain analysis 9

1.3.1 Describing signals and processors 9

$\begin{array}{ll}\text { 1.3.2 Digital convolution } & 14\end{array}$

1.4 Fourier Analysis 19

1.4.1 The Discrete Fourier Series 20

1.4.2 The Fourier Transform 26

1.5 The $z$-Transform 34

1.5.1 Definition and properties 34

1.5.2 z-Plane poles and zeros $\quad 39$

Problems 45

2 Digital Filter Design 53

2.1 Non-recursive filters $\quad 54$

2.1.1 Introduction 54

2.1.2 The Fourier Transform method 56

2.1.3 Window functions $\quad 60$

2.1.4 Equiripple filters $\quad 67$

2.2 Recursive filters 71

2.2.1 Introduction $\quad 71$

2.2.2 The bilinear transformation $\quad 73$

2.2.3 Impulse-invariant filters $\quad 81$

Problems $\quad 86$

3 The Discrete and Fast Fourier Transforms 90

3.1 The Discrete Fourier Transform (DFT) 90

3.2 The Fast Fourier Transform (FFT) 94

3.2.1 Basis of the FFT 94 
3.2.2 Index mapping 96

3.2.3 Twiddle factors and FFT butterflies 99

3.2.4 Decimation-in-time algorithms 103

3.2.5 Decimation-in-frequency algorithms 108

3.2.6 FFT processing 113

3.2.7 Fast convolution 119

Problems 123

4 Describing Random Sequences 127

4.1 Introduction 127

4.2 Basic measures of random sequences 129

4.2.1 Amplitude distribution 129

4.2.2 Mean, mean-square and variance 133

4.2.3 Ensemble averages and time averages $\quad 136$

4.2.4 Autocorrelation 139

4.2.5 Power spectrum 144

4.2.6 Cross-correlation 149

4.2.7 Cross-spectrum 152

Problems 153

5 Processing Random Sequences 156

5.1 Response of linear processors $\quad 156$

5.2 White noise through a filter 162

5.3 System identification by cross-correlation 168

5.4 Signals in noise 171

5.4.1 Introduction 171

5.4.2 Signal recovery 173

5.4.3 Matched filter detection $\quad 178$

5.4.4 Signal averaging 183

$\begin{array}{ll}\text { Problems } & 184\end{array}$

Appendix A: Computer Programs 188

A.1 List of programs and introductory notes 188

$\begin{array}{ll}\text { A.2 BASIC programs } & 189\end{array}$

A.3 PASCAL programs 197

Appendix B: Tables of Fourier and z-Transforms 208

B.1 The Discrete Fourier Series: properties 208

B.2 The Fourier Transform of aperiodic digital signals: properties and pairs 209

B.3 The unilateral $z$-Transform: pairs 210

B.4 The unilateral $z$-Transform: properties 211

B.5 The Discrete Fourier Transform: properties 212 
Answers to Selected Problems

Bibliography

217

Index 


\section{Series Editor's Foreword}

The rapid development of electronics and its engineering applications ensures that new topics are always competing for a place in university and polytechnic courses. But it is often difficult for lecturers to find suitable books for recommendation to students, particularly when a topic is covered by a short lecture module, or as an 'option'.

This Series offers introductions to advanced topics. The level is generally that of second and subsequent years of undergraduate courses in electronic and electrical engineering, computer science and physics. Some of the authors will paint with a broad brush; others will concentrate on a narrower topic, and cover it in greater detail. But in all cases the titles in the Series will provide a sound basis for further reading of the specialist literature, and an up-to-date appreciation of practical applications and likely trends.

The level, scope and approach of the Series should also appeal to practising engineers and scientists encountering an area of electronics for the first time, or needing a rapid and authoritative update.

Paul A. Lynn 


\section{Preface}

In putting together this short text on Digital Signal Processing (DSP), I have had three main objectives. Firstly, I wanted to provide undergraduate students - as well as postgraduates and practising engineers needing an introduction to the field - with a concise and accessible account of the theoretical background to DSP and its practical applications. Secondly, since it is now commonplace for the individual to own (or have ready access to) a personal computer, I decided to illustrate key DSP topics and design methods with computer programs. And finally, knowing that most newcomers to DSP find the topic of digital noise, and signals in noise, especially difficult, I have included introductory chapters on the description and processing of random sequences.

Some of these objectives perhaps deserve a little more explanation. As far as the computer programs are concerned, I feel sure that there is a great deal to be gained, in both confidence and understanding, by using and modifying DSP programs on a general-purpose computer, and by seeing the results of digital processing build up on a computer screen. A large number of figures in the text have been produced in this way, and I hope that many of my readers will have the chance to reproduce the graphical outputs, and experiment with further programs of their own. Incidentally, quite a number of the figures have previously been used in my book Introductory Digital Signal Processing with Computer Applications, coauthored with Wolfgang Fuerst and published by Wiley in 1989, and I am grateful for the publisher's agreement to include them. The programs are listed in both BASIC and PASCAL in Appendix A, and although they cannot do more than indicate some of the possibilities of this approach to teaching and learning DSP, I hope they will be found useful.

As far as noise, and signals in noise, are concerned, many years of teaching these topics (in both analog and digital versions) convinced me that an approach with copious illustrations should be attractive to students and allow them to visualise the essential mathematical background. The mathematics itself I have kept as simple as possible, consistent with the need for accuracy; and I have tried, at every stage, to illustrate the main theoretical results by involving the reader in the actual business of 
processing random digital signals and noise sequences on a digital computer.

Of course, any book of this length on a huge subject must be selective. I decided early on that it would be sensible to cover the basic theory of linear DSP and its application using general-purpose computers reasonably thoroughly, but omit any material on hardware or VLSI aspects. The result is inevitably a compromise, but one which I trust will appeal across a wide range of engineering and scientific disciplines, especially to those who need an accessible introduction without getting involved, so to speak, in the nuts and bolts of the subject.

Paul A. Lynn

Bristol, 1992 